\title{
Penerapan Lean Manufacturing dengan Metode VSM dan FMEA untuk Mereduksi Pemborosan Produksi Sarden
}

\author{
Haris Dwi Armyanto1), Dwi Djumhariyanto2), Santoso Mulyadi3) \\ ${ }^{1}$ Jurusan Teknik Mesin Universitas Jember, Kampus Tegal Boto Jember \\ Naskah diterima 19/11/2019; direvisi 06/04/2020; disetujui 16/04/2020 \\ doi: https://doi.org/10.24843/JEM.2020.v13.i01.p07
}

\begin{abstract}
Abstrak
CV.X merupakan salah satu perusahaan pengolahan sarden yang terletak di Banyuwangi. Pada proses produksi di perusahaan masih ditemukan beberapa pemborosan (waste). Untuk mengurangi pemborosan yang terjadi digunakan pendekatan lean manufacturing dengan metode Value Stream Mapping (VSM) untuk pemetaan aliran produksi dan aliran informasi terhadap proses produksi dari awal bahan baku hingga produk jadi dan dikirim ke konsumen, serta analisis dengan metode Failure Mode and Effects Analysis (FMEA) untuk mengetahui penyebab kegagalan proses yang paling prioritas dan perlu dilakukan perbaikan dengan segera. Identifikasi pemborosan diawali dengan penggambaran current state map, lalu dilakukan analisis pemborosan ke dalam kategori 7 pemborosan [1]. Pada analsis tersebut ditemukan 3 jenis pemborosan yaitu waiting time, unnecessary inventory dan defect (kembung). Setelah itu dilakukan analisis akar penyebab timbulnya pemborosan menggunakan fishbone diagram, dan analis FMEA untuk mengetahui nilai RPN tertinggi yang selanjutnya akan menjadi prioritas pemberian usulan perbaikan yang tepat dan sesuai dengan masalah dan kondisi proses produksi sarden $125 \mathrm{~g}$ di CV.X. Rekomendasi perbaikan yang diberikan terhadap pemborosan dengan nilai RPN tertinggi antara lain Menambahkan mesin pencuci produk untuk mengurangi penumpukan produk dan waktu tunggu yang ada sehingga pemborosan waiting time dan unnecessary inventory dapat berkurang, mengganti sarung tangan kain dengan lateks, serta menjaga kebersihan nampan ikan.
\end{abstract}

Kata Kunci: Lean manufacturing, value stream mapping, failure mode and effect analysis

\section{Abstract}

CV.X is a sardine processing company located in Banyuwangi. In the company production process, there are some wastes. To reduce the waste that occurs, lean manufacturing approach using Value Stream Mapping (VSM) method is used to map the production flow and information flow to the production process from the beginning of the raw material to the finished product and sent to consumers, as well as analysis using the Failure Mode and Effects Analysis (FMEA) method. ) to find out what causes the most priority process failures and needs immediate improvement. Waste identification is preceded by a depiction of the current state map, then waste analysis is conducted into category 7 waste. In this analysis, there are 3 types of waste, which are waiting time, unnecessary inventory and defects. After that an analysis of the root causes of waste occurs using fishbone diagrams, and FMEA analysts to find out the highest RPN value which will then be prioritized for giving recommendations for an appropriate improvement and in accordance with the problems and conditions of the $125 \mathrm{~g}$ sardine production process in CV.X. Improvement recommendations given for waste with the highest RPN value include adding a product washer to reduce product buildup and waiting times so that waiting time and unnecessary inventory waste can be reduced, replacing cloth gloves with latex, and keeping the fish tray clean.

Keywords: Lean manufacturing, value stream mapping, failure mode and effect analysis

\section{Pendahuluan}

CV.X merupakan salah satu perusahaan pengolahan ikan di Banyuwangi dimana sarden menjadi produk utamanya. Adapun produk lain yang dihasilkan yaitu mackerel dan tuna. Penelitian di CV.X dilakukan pada produk sarden dengan ukuran 125 gram, karena produk ini merupakan produk utama dari perusahaan, yang permintaannya sangat besar.

Pada dasarnya lean adalah konsep perampingan atau efisiensi, dimana konsep ini dapat diterapkan pada industri manufaktur atau jasa. Konsep lean thinking diprakarsai oleh sistem produksi Toyota di Jepang, lean dirintis oleh Taichi Ohno dan Sensei Shigeo Shingo dimana implementasi dari konsep ini didasarkan pada 5 prinsip utama [2] yaitu, specify menentukan manakah yang dapat memberikan nilai dan manakah yang tidak, bukan dilihat dari sudut pandang perusahaan melainkan dilihat dari sudut pandang konsumen. Identify, yaitu mengidentifikasi tahapan - tahapan yang diperlukan, mulai dari proses desain, pemesanan, dan pembuatan produk berdasarkan keseluruhan value stream untuk menemukan pemborosan yang tidak memiliki nilai tambah. Flow, yaitu melakukan aktivitas yang dapat menciptakan suatu nilai tanpa adanya gangguan, proses rework, aliran balik, aktivitas menunggu (waiting) ataupun sisa produksi. Pulled, mengetahui aktivitas - aktivitas penting yang digunakan dalam membuat apa yang diinginkan oleh konsumen. Perfection, yaitu berusaha mencapai kesempurnaan 
dengan menghilangkan waste (pemborosan) secara bertahap dan berkelanjutan (continuous).

Lean manufacturing dapat diterapkan dengan menggunakan berbagai metode, salah satunya VSM dan FMEA. Value Stream Mapping atau VSM adalah suatu metode pemetaan semua aktivitas baik bernilai tambah (value added) maupun tidak bernilai tambah (non value added) yang diperlukan untuk menyelesaikan suatu produk dari raw material sampai produk jadi [3]. Failure Mode and Effects Analysis (FMEA) untuk menganalisis penyebab kegagalan proses dilantai produksi. FMEA pada penelitian ini digunakan untuk mengidentifikasi potensi penyebab kegagalan yang menjadi prioritas dan perlu dilakukan perbaikan dengan segera.

\section{Metode Penelitian}

Langkah-langkah yang dilakukan dalam penelitian ini yaitu sebagai berikut.

\section{Survey lapangan}

Dilakukan untuk mengetahui kondisi lapangan dalam hal ini perusahaan untuk memastikan data yang diperlukan tersedia. Survey sangat penting bagi peneliti untuk memberikan gambaran yang jelas pada objek penelitiannya.

2. Studi literatur

Digunakan untuk mendalami teori dan ilmu pengetahuan yang berkaitan dengan topik penelitian.

3. Pengamatan proses produksi

Pengamatan proses produksi dilakukan untuk mempelajari dan mengamati setiap proses produksi yang ada.

4. Pengumpulan data

Pada tahap ini dilakukan pengumpulan data yang diperlukan dalam penelitian, antara lain:

a. Waktu siklus

b. Data produksi

c. Jumlah operator

d. Data produk cacat

5. Pengolahan data

Tahapan pengolahan data adalah sebagai berikut:

a. Pembuatan current state map

Merupakan pemetaan semua aktivitas yang diperlukan untuk menyelesaikan suatu produk dari raw material sampai produk jadi. Kemudian dilanjutkan dengan pengelompokan proses produksi apakah tergolong valueable activity (VA), atau non-valueable activity (NVA).

b. Identifikasi pemborosan

Identifikasi pemborosan dilakukan dengan identifikasi secara manual (analisa lapang dan wawancara) terhadap 7 waste.

c. Menentukan akar permasalahan dengan fishbone diagram

Konsep dari fishbone diagram adalah permasalahan mendasar diletakkan pada bagian kanan dari diagram atau pada bagian kepala dari kerangka tulang ikan. Penyebab permasalahan digambarkan pada sirip dan durinya [4]. Dengan fishbone diagram akan diketahui beberapa penyebab pemborosan yang potensial dimana selanjutnya dianalisis menggunakan FMEA untuk mengetahui nilai RPN tertinggi.

d. Analisis FMEA

Dilakukan dengan memberikan rating pada severity, occurance, dan detection serta mengalikan ketiga indikator sehingga diperoleh nilai RPN. Nilai RPN tertinggi digunakan untuk menentukan penyebab manakah yang paling potensial dan perlu dilakukan perbaikan dengan segera.

e. Memberikan rekomendasi perbaikan

Rekomendasi perbaikan diberikan terhadap penyebab pemborosan dengan hasil RPN tertinggi.

\section{Hasil dan Pembahasan}

\subsection{Pembuatan Value Stream Map}

Value Stream Map (VSM) adalah gambaran dari seluruh proses produksi dari bahan baku (raw material) hingga produk diterima konsumen. Pada VSM dilengkapi informasi pada setiap stasiun produksi seperti waktu siklus, dan jumlah operator. Adapun VSM pada penelitian ini dapat dilihat pada gambar 1. Selanjutnya dengan VSM dapat dilakukan pengelompokan proses produksi kedalam 3 kategori yaitu valueable activity (VA), necessarry but nonvalueable activity (NBVA), dan non-valueable activity yang disajikan dalam tabel 1.

\subsection{Identifikasi Pemborosan (waste)}

Adapun identifiakasi pemborosan dengan melakukan analisis lapangan dan wawancara pada proses produksi sarden $125 \mathrm{~g} \mathrm{CV.X}$ adalah sebagai berikut:

\section{Produksi berlebih (Overproduction)}

Pada proses produksi CV.X menggunakan sistem membuat berdasarkan adanya pesanan (make to order), sehingga pada perusahaan ini jumlah output produk yang dihasilkan tidak pernah mengalami overproduction dalam jumlah yang besar atau melebihi toleransi perusahaan (10\%).

2. Waktu menunggu (Waiting time)

Terdapat pemborosan waktu tunggu pada proses produksi sarden $125 \mathrm{~g}$ di CV.X. Hal ini dapat diketahui pada value stream map dimana waktu tunggu terbesar terjadi selama 68.400 detik pada saat produk telah didinginkan dan akan dilakukan proses pencucian. Jumlah produk yang sangat banyak menyebabkan produk menunggu dan mengantri untuk dilakukan pencucian, dimana hal ini juga mempengaruhi adanya pemborosan unnecessary inventory.

3. Transportasi (Transportation)

Pada proses produksi yang ada pada CV.X tidak ditemukan adanya pemborosan transportasi. Setiap transportasi yang ada pada proses produksi sesuai dengan prosedur, efisien, dan bernilai tambah.

4. Proses berlebih (Overprocessing)

Pada proses produksi yang ada pada CV.X tidak ditemukan adanya pengulangan proses yang dirasa kurang penting ataupun pemborosan proses yang tidak menghasilkan nilai tambah.

5. Persediaan berlebih (Unnecessarry iventory) 
Pada proses produksi sarden $125 \mathrm{~g}$ di CV.X tidak ditemukan adanya pemborosan berupa inventory dalam bentuk produk jadi maupun dalam bentuk bahan baku. Tetapi terdapat penumpukan produk atau Work in Process (WIP) saat produk akan memasuki proses pencucian. Hal ini berkaitan dengan adanya pemborosan berupa waktu tunggu (waiting time) selama 68.400 detik. Produk yang telah diproses pada tahap retorting selanjutnya didinginkan dengan media udara (didiamkan), produk yang sudah dingin selanjutnya dilakukan proses pencucian, disini produk mengantri dan menunggu untuk pencucian dan menyebabkan pemborosan unnecessary inventory.

6. Gerakan yang tidak perlu (Motion)

Tidak teridentifikasi adanya gerakan-gerakan yang tidak diperlukan yang dapat menyebabkan pemborosan dalam proses produksi sarden $125 \mathrm{~g}$ di CV.X sehingga tidak ada pemborosan dalam bentuk gerakan yang tidak perlu.
7. Produk cacat (Defect)

Dalam proses produksi sarden $125 \mathrm{~g}$ di CV.X terdapat beberapa jenis cacat produk, diantaranya bocor (b), penyok (p), kembung (k), dan drop (d) atau lipatan kaleng tidak sempurna. Tabel 2 menyajikan data jumlah produksi dan cacat yang terjadi pada produk sarden $125 \mathrm{~g}$ selama bulan Januari - Maret 2019.

Selanjutnya data-data di atas disajikan dalam bentuk diagram pareto sehingga untuk mengetahui produk cacat terbesar. Masalah yang paling banyak terjadi ditunjukkan oleh grafik batang pertama yang tertinggi yang mana ditempatkan pada sisi paling kiri dan seterusnya sampai masalah yang paling sedikit terjadi ditunjukkan oleh grafik batang terakhir yang terendah serta ditempatkan pada sisi paling kanan [5]. Pareto diagram terdapat pada Gambar 2. Pada pereto diagram diperoleh cacat tertinggi yaitu kembung.

Tabel 1. Pengelompokan VA, NVA, dan NBVA

\begin{tabular}{|c|c|c|c|}
\hline No. & Aktivitas & $\begin{array}{l}\text { Waktu } \\
\text { (detik) }\end{array}$ & Kategori \\
\hline 1. & $\begin{array}{l}\text { Inventori awal raw materia/ yang datang dengan } \\
\text { menaruhnya di bak penampungan. }\end{array}$ & 54.000 & NBVA \\
\hline 2. & $\begin{array}{l}\text { Raw material ditransfer ke proses pencucian dan } \\
\text { pengguntingan. }\end{array}$ & 120 & NVA \\
\hline 3. & $\begin{array}{l}\text { Proses pencucian dan pengguntingan ikan untuk } \\
\text { menghilangkan kepala, isi perut, dan ekor. }\end{array}$ & 1.462 & VA \\
\hline 4. & $\begin{array}{l}\text { Ikan yang sudah dipotong ditransfer ke tempat pengisian } \\
\text { kaleng. }\end{array}$ & 90 & NVA \\
\hline 5. & Ikan dimasukkan ke dalam kaleng. & 2.366 & VA \\
\hline 6. & Ikan dalam kaleng ditransfer ke proses pre-cooking. & 120 & NVA \\
\hline 7. & Ikan menunggu untuk diproses di pre-cooking. & 360 & NVA \\
\hline 8. & Proses pre-cooking dengan menggunakan steam. & 747 & VA \\
\hline 9. & Produk selanjutnya ditransfer ke proses medium filling. & 30 & NVA \\
\hline 10. & Ikan menunggu untuk diproses sembari ditiriskan. & 660 & NBVA \\
\hline 11. & $\begin{array}{l}\text { Ikan diproses ke medium filling atau penambahan media } \\
\text { berupa minyak. }\end{array}$ & 509 & VA \\
\hline 12. & $\begin{array}{l}\text { Produk ditransfer ke proses seaming atau penutupan } \\
\text { kaleng. }\end{array}$ & 15 & NVA \\
\hline 13. & Produk diproses pada seaming area. & 502 & VA \\
\hline 14. & Produk ditransfer ke proses retorting. & 50 & NVA \\
\hline 15. & Produk menunggu untuk dilakukan proses retort. & 2.100 & NBVA \\
\hline 16. & $\begin{array}{l}\text { Proses retorting atau sterilisasi dengan suhu dan } \\
\text { tekanan sesuai standar perusahaan. }\end{array}$ & 6.300 & VA \\
\hline 17. & Produk ditransfer ke tempat pencucian. & 570 & NVA \\
\hline 18. & $\begin{array}{l}\text { Produk menunggu untuk dicuci sembari didinginkan } \\
\text { dengan udara. }\end{array}$ & 68.400 & NBVA \\
\hline 19. & Produk dicuci dengan air dan sabun. & 461 & VA \\
\hline 20. & $\begin{array}{l}\text { Produk ditransfer ke proses pengeprinan tanggal } \\
\text { kadaluarsa. }\end{array}$ & 35 & NVA \\
\hline 21. & Proses pengeprinan tanggal kadaluarsa. & 273 & VA \\
\hline 22. & Produk ditransfer ke proses pengemasan dalam karton. & 6 & NVA \\
\hline 23. & Proses pengemasan ke dalam karton. & 1.176 & VA \\
\hline 34. & Produk (finish good) ditransfer ke area penyimpanan. & 90 & NVA \\
\hline
\end{tabular}




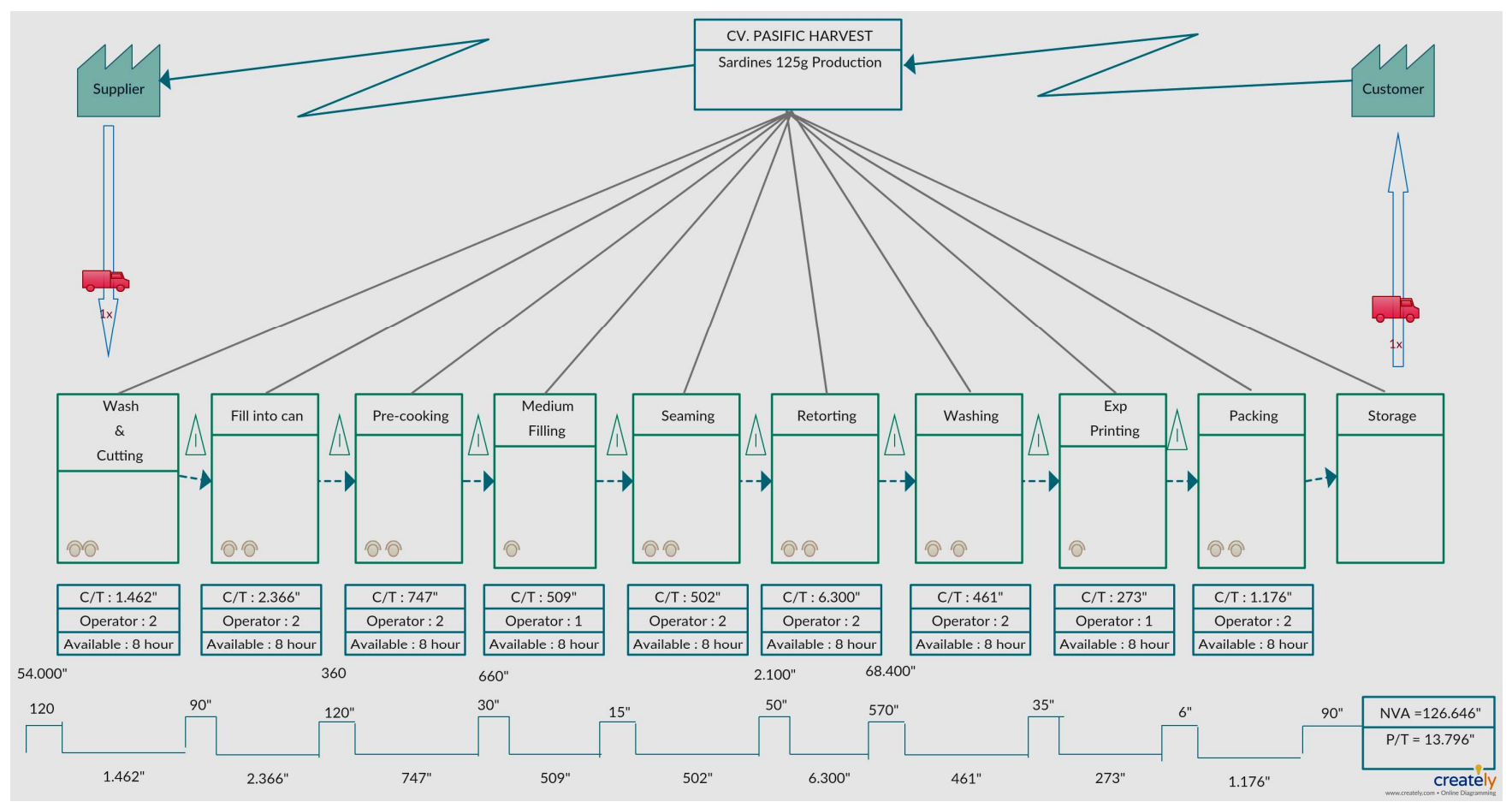

Gambar 1. Value Stream Mapping

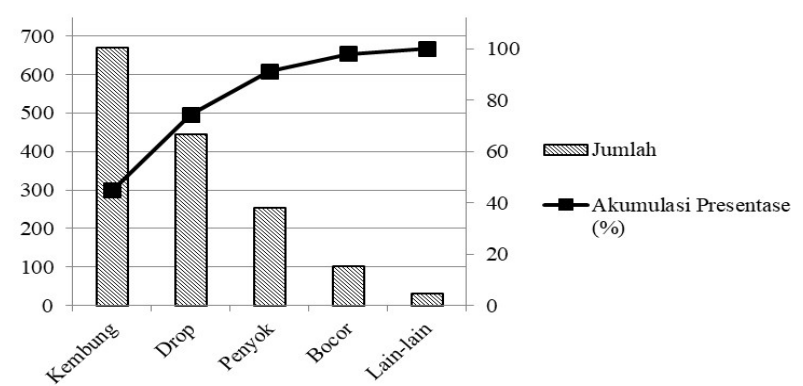

Gambar 2. Pareto diagram produk cacat

\subsection{Analisis timbulnya waste}

Pada tahap ini dilakukan analisis menggunakan fishbone diagram untuk mengetahui penyebab-penyebab adanya waste yang potensial yang dilakukan secara brainstorming dengan pihak perusahaan.

\section{Waiting time}

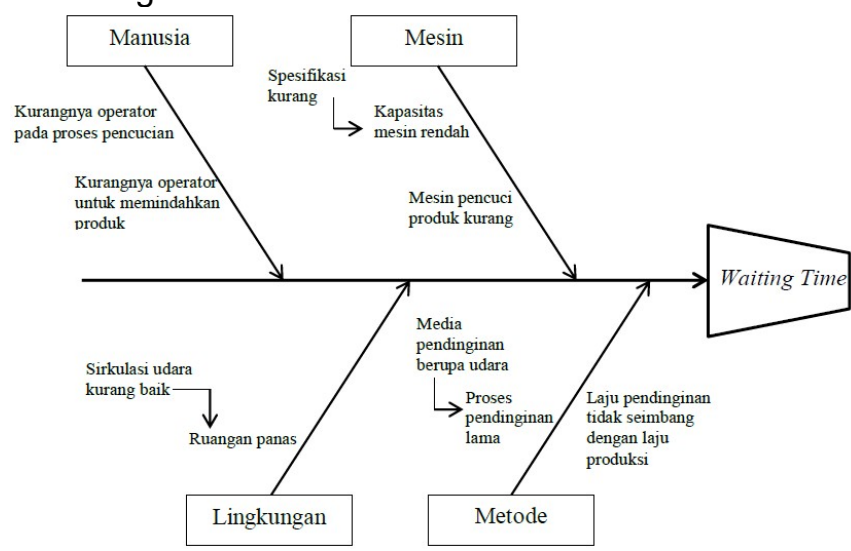

Gambar 3. Fishbone waiting time

Penyebab yang paling potensial dari diagram di atas antaralain :

a. Mesin pencuci produk kurang.

b. Sirkulasi udara kurang baik. c. Media pendinginan dengan udara tanpa alat bantu

\section{Unnecessary inventory}

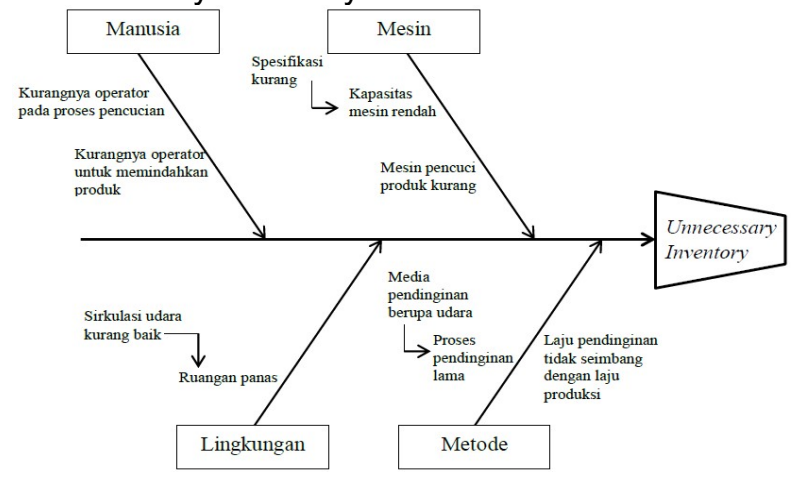

Gambar 4. Fishbone unnecessary inventory

Penyebab yang paling potensial dari diagram di atas antaralain :

a. Mesin pencuci produk kurang.

b. Sirkulasi udara kurang baik.

c. Media pendinginan dengan udara tanpa alat bantu.

\section{Defect (kembung)}

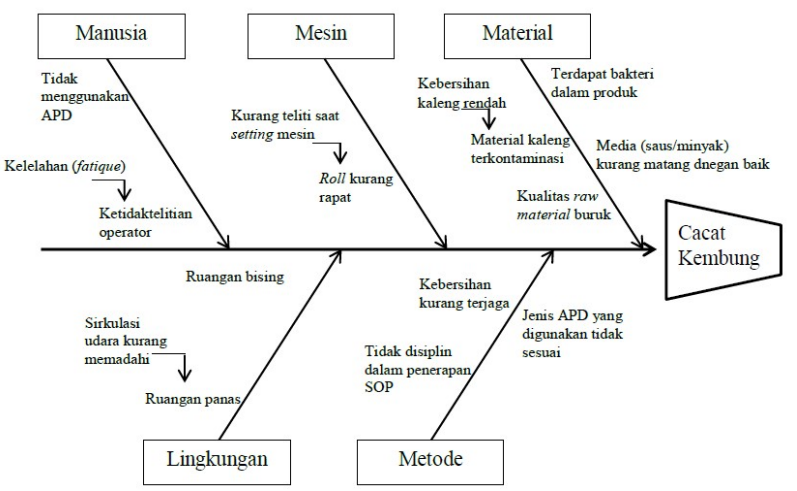

Gambar 5. Fishbone Defect 
Penyebab yang paling potensial dari diagram di atas antaralain :

a. Terdapat bakteri dalam produk.

b. Kualitas raw material (ikan) buruk

\subsection{Analisis FMEA}

Dilakukan untuk memperoleh nilai RPN tertinggi dengan mengalikan nilai indikator severity, occurence, detection. Nilai indikator tersebut diperoleh secara brainstorming menggunakan skala likert $1-5$.

1. Severity

Merupakan tingkat keseriusan dari pemborosan yang terjadi. Berikut ini adalah tabel severity untuk masing-masing pemborosan.

2. Occurence

Merupakan tingkat sering terjadinya (frekuensi) pemborosan tersebut terjadi.

3. Detection

Indikator yang memeringkatkan kemudahan dari pemborosan tersebut dapat dideteksi.

Tabel 3. Nilai skala liket severity dan occurence

\begin{tabular}{cc}
\hline Rating & Effect \\
\hline 1 & Tidak ada / sangat \\
2 & ringan \\
3 & Ringan \\
4 & Sedang \\
5 & Tinggi \\
\hline
\end{tabular}

Tabel 4. Nilai skala liket detection

\begin{tabular}{cc}
\hline Rating & Effect \\
\hline 1 & Sangat tinggi \\
2 & Tinggi \\
3 & Jarang \\
4 & Sangat jarang \\
5 & Hampir tidak mungkin \\
\hline
\end{tabular}

Langkah selanjutnya yaitu membuat matriks FMEA dimana di dalam nya juga terdapat perhitungan RPN sehingga nantinya diketahui nilai tertinggi sebagai penyebab yang paling prioritas dan harus diperbaiki dengan segera. Matriks FMEA dapat dilihat pada Tabel 5.

\subsection{Rekomendasi Perbaikan}

Rekomendasi perbaikan diberikan terhadap nilai RPN tertinggi pada ketiga jenis pemborosan. Rekomendasi yang dapat diberikan sesui penyebab dengan RPN tertinggi yaitu:

1. Penambahan mesin pencuci produk

Sesuai hasil analisis RPN terbesar, penyebab adanya pemborosan waiting time dan unnecessary inventory keduanya sama, yaitu kurangnya mesin pencuci produk, maka rekomendasi yang dapat diberikan yaitu dengan penambahan unit mesin pencuci produk. Pada proses produksi sarden $125 \mathrm{~g}$ CV.X hanya terdapat 1 unit mesin pencuci produk yang dirancang khusus menyesuaikan kebutuhan perusahaan dengan kemampuan 156 kaleng/menit. Pada keadaan lapangan kemampuan mesin tersebut masih kurang sehingga menyebabkan waste, untuk itu perlu adanya penambahan unit mesin pencuci produk agar tidak terjadi waktu tunggu dan penumpukan produk yang besar setelah produk dilakukan proses retorting. Dengan ditambahnya mesin pencuci produk, maka waktu produksi sarden $125 \mathrm{~g}$ otomatis juga dapat berkurang.

2. Menjaga kebersihan nampan ikan dan penegasan penggunaan APD

Pada analisis RPN menunjukkan nilai terbesar penyebab cacat kembung yaitu adanya bakteri dalam produk. Rekomendasi perbaikan yang dapat diberikan yaitu dengan menjaga kebersihan nampan wadah ikan. Pencucian wadah ikan harus dilakukan setiap hari setelah proses produksi selesai. Perlu juga memastikan keadaan media (saus) dalam keadaan panas saat penuangan, hal ini bertujuan untuk mencegah adanya oksigen dalam produk yang dapat mempengaruhi pertumbuhan bakteri, serta mengganti penggunaan sarung tangan kain dengan sarung tangan lateks. Penggunaan sarung tangan kain kurang tepat karena bahan dasar kain memiliki sifat mudah lembab dan mudah bagi bakteri untuk tumbuh.

\section{Simpulan}

Kesimpulan yang didapat berdasarkan analisis data yang telah dilakukan pada penelitian ini antara lain sebagai berikut:

1. Terdapat 3 jenis pemborosan (waste) yang teridentifikasi yaitu waiting time, unnecessary inventory dan defect (kembung).

2. Faktor yang mempengaruhi adanya kedua jenis pemborosan yang teridentifikasi tersebut antara lain sebagai berikut :

- Waiting time dan unnecessary inventory karena keduanya berkaitan erat dan disebabkan oleh unit mesin pembersih produk yang kurang. Kurangnya mesin pencuci menyebabkan adanya penumpukan produk sehingga terjadi waktu tunggu.

- Defect kembung disebabkan adanya pertumbuhan bakteri dalam kaleng.

3. Rekomendasi perbaikan yang dapat diberikan antara lain

- Menambahkan mesin pencuci produk, sehingga pemborosan waiting time dan unnecessary inventory dapat berkurang. Pada proses produksi sarden $125 \mathrm{~g} \mathrm{CV}$.X hanya terdapat 1 unit mesin pencuci produk yang dirancang khusus menyesuaikan kebutuhan perusahaan dengan kemampuan 156 kaleng/menit, namun pada keadaan lapangan kemampuan mesin tersebut masih kurang.

- Melakukan penegasan terhadap kelengkapan karyawan berupa penggunaan sepatu, baju produksi, masker, penutup rambut, dan mengganti penggunaan sarung tangan kain dengan sarung tangan lateks. Memastikan suhu media (saus) dalam kondisi panas saat penuangan serta membersihkan nampan ikan setiap hari setelah produksi selesai agar kebersihan tetap terjaga. 


\begin{tabular}{|c|c|c|c|c|c|c|c|}
\hline \multicolumn{3}{|c|}{$\begin{array}{l}\text { Product : Sardine } 125 \mathrm{~g} \\
\text { Date completed : } 20 \mathrm{April} 2019\end{array}$} & \multicolumn{5}{|c|}{ Completed by : Haris Dwi A } \\
\hline $\begin{array}{l}\text { Failure } \\
\text { Mode }\end{array}$ & Cause Failure & $\mathbf{S}$ & 0 & D & $\begin{array}{c}\text { RPN } \\
\text { (SxOxD) }\end{array}$ & $\begin{array}{c}\text { Rekomendasi } \\
\text { Perbaikan }\end{array}$ & Indikator/Validasi \\
\hline \multirow{4}{*}{$\begin{array}{l}\text { Waiting } \\
\text { Time }\end{array}$} & $\begin{array}{l}\text { Kurangnya } \\
\text { mesin pencuci } \\
\text { produk (hanya } 1 \\
\text { unit) }\end{array}$ & 4 & 3 & 1 & 12 & \multirow{3}{*}{$\begin{array}{l}\text { Menambahkan unit } \\
\text { pencuci, hal ini juga } \\
\text { dapat memangkas } \\
\text { waktu produksi. } \\
\text { Memperbaiki sirkulasi } \\
\text { udara dengan } \\
\text { mengatur atau } \\
\text { menambahkan } \\
\text { ventilasi udara. } \\
\text { Menambahkan alat } \\
\text { bantu pendingin } \\
\text { berupa blower atau } \\
\text { sejenisnya untuk } \\
\text { membantu proses } \\
\text { pendinginan. }\end{array}$} & $\begin{array}{l}\text { Produk mengantri } \\
\text { saat memasuki } \\
\text { proses pencucian }\end{array}$ \\
\hline & $\begin{array}{l}\text { Sirkulasi udara } \\
\text { buruk (luas } \\
\text { lubang ventilasi } \\
<5 \% \text { luas lantai) }\end{array}$ & 3 & 2 & 1 & 6 & & $\begin{array}{l}\text { Ruangan panas, } \\
\text { proses pendinginan } \\
\text { menjadi lebih lama }\end{array}$ \\
\hline & $\begin{array}{l}\text { Tidak ada alat } \\
\text { bantu (blower, } \\
\text { dil) }\end{array}$ & 2 & 1 & 1 & 2 & & $\begin{array}{l}\text { Tidak ada alat bantu } \\
\text { untuk mendinginkan } \\
\text { produk }\end{array}$ \\
\hline & $\begin{array}{l}\text { Kurangnya } \\
\text { mesin pencuci } \\
\text { produk (hanya } 1 \\
\text { unit) }\end{array}$ & 4 & 3 & 1 & 12 & $\begin{array}{l}\text { Menambahkan unit } \\
\text { pencuci, hal ini juga } \\
\text { dapat memangkas } \\
\text { waktu produksi. }\end{array}$ & $\begin{array}{l}\text { Produk mengantri } \\
\text { saat memasuki } \\
\text { proses pencucian }\end{array}$ \\
\hline \multirow[t]{2}{*}{$\begin{array}{c}\text { Unnecessa } \\
\text { ry } \\
\text { Inventory }\end{array}$} & $\begin{array}{l}\text { Sirkulasi udara } \\
\text { buruk (luas } \\
\text { lubang ventilasi } \\
<5 \% \text { luas lantai) }\end{array}$ & 3 & 2 & 1 & 6 & $\begin{array}{l}\text { Memperbaiki sirkulasi } \\
\text { udara dengan } \\
\text { mengatur atau } \\
\text { menambahkan } \\
\text { ventilasi udara. }\end{array}$ & $\begin{array}{l}\text { Ruangan panas, } \\
\text { proses pendinginan } \\
\text { menjadi lebih lama }\end{array}$ \\
\hline & $\begin{array}{l}\text { Tidak ada alat } \\
\text { bantu (blower, } \\
\text { dII) }\end{array}$ & 2 & 1 & 1 & 2 & $\begin{array}{l}\text { Menambahkan alat } \\
\text { bantu pendingin } \\
\text { berupa blower atau } \\
\text { sejenisnya untuk } \\
\text { membantu proses } \\
\text { pendinginan. }\end{array}$ & $\begin{array}{l}\text { Tidak ada alat bantu } \\
\text { untuk mendinginkan } \\
\text { produk }\end{array}$ \\
\hline \multirow{2}{*}{$\begin{array}{c}\text { Cacat } \\
\text { Kembung }\end{array}$} & $\begin{array}{l}\text { Terdapat bakteri } \\
\text { dalam produk }\end{array}$ & 4 & 3 & 3 & 36 & $\begin{array}{l}\text { Meningkatkan dan } \\
\text { menjaga kebersihan } \\
\text { baik dari kebersihan } \\
\text { alat (equipment) } \\
\text { maupun kebersihan } \\
\text { pekerja (penggunaan } \\
\text { sarung tangan lateks, } \\
\text { masker, penutup } \\
\text { kepala, dan baju } \\
\text { produksi). }\end{array}$ & $\begin{array}{l}\text { Produk } \\
\text { mengembung, } \\
\text { indikasi adanya } \\
\text { bakteri. Banyak } \\
\text { karyawan tidak } \\
\text { mengenakan APD } \\
\text { secara lengkap, dan } \\
\text { jenis sarung tangan } \\
\text { yang digunakan } \\
\text { kurang tepat. }\end{array}$ \\
\hline & $\begin{array}{l}\text { Kualitas raw } \\
\text { material (ikan) } \\
\text { buruk }\end{array}$ & 3 & 2 & 3 & 18 & $\begin{array}{l}\text { Melakukan } \\
\text { pemeriksaan } \\
\text { terhadap raw material } \\
\text { (ikan) yang diperoleh } \\
\text { dari supplier untuk } \\
\text { memastikan ikan } \\
\text { dalam kondisi segar, } \\
\text { dan melakukan } \\
\text { penyimpanan di cold } \\
\text { storage. }\end{array}$ & $\begin{array}{l}\text { Ikan terlihat tidak } \\
\text { segar, bagian tubuh } \\
\text { terpotong/hancur }\end{array}$ \\
\hline
\end{tabular}

\section{Daftar Pustaka}

[1] Liker, J., dan D. Meier, The Toyota Way Field Book. New York: McGraw-Hill Education, 2006.

[2] Hines, P., dan D Taylor. Going Lean. Cardiff, United Kingdom: Lean Enterprose Reasearch Centre, 2000.

[3] Rother, M., dan J. Shook, Learning to See Value Stream Mapping to Create Value and Eliminate Muda. Version 1.2, Brookline: Lean Enterprise Institute, 1999.

[4] Scavarda J. A., T. Bouzdine-Chameeva, S. M. Goldstein, J. M. Hays, dan A. V. Hill., A Review of The Casual Mapping Practice and Research Literature. Second World Conference on POM and 15th Annual POM Conference, Mexico, 2004.

[5] Gaspersz, V., Manajemen Produktivits Total, Strategi Peningkatan Produktivitas Bisnis Global. Jakarta: PT. Gramedia Pustaka Utama, 1998. 